\title{
Comparative Analysis of Social Cohesion and Task Cohesion in the Context of Tunisian Professional Football
}

\author{
Oussema SGHARI ${ }^{1}$, Aicha JLASSI ${ }^{2}$, Imen BEN AMAR ${ }^{2}$, Ali ELLOUMI ${ }^{3 *}$, Bachir ZOUDJI ${ }^{4}$ \\ ${ }^{1}$ Faculty of letters and arts de University of Sfax. Tunisie \\ ${ }^{2}$ Laboratoy ECUMUS- Faculty of letters and arts- University of Sfax. Tunisie \\ ${ }^{3}$ Laboratory TEC - University Paris Descartes. France \\ ${ }^{4}$ Faculty of sport, University of Valenciennes, France
}

*Corresponding Author: Ali ELLOUMI, Laboratory TEC - University Paris Descartes. France

\begin{abstract}
The purpose of this research is to provide some answers to this fundamental question: What is the most relevant dimension of cohesion; Is the social or the operative for the success of a professional football team? And analyze the four factors of cohesion; individual social and task attraction and social and task integration within a group. Our method is purely quantitative, it is through the use of questionnaire (group environment questionnaire) Carron et al (1985) (1) and its translations ; French, Heuzé and Fontayne (2002) (2) and Arabic, Boughattas and Kridis (2016) (3). Our results show that the success of the team is based on two dimensions of cohesion. In addition, according to our analysis we can say that the task cohesion to more important averages than the social performance of the teams while the social ranks on the operating side of the teams less efficient. In conclusion, the success of a team is based on several intertwined factors whose cohesion mediates all these factors.
\end{abstract}

Keywords: Social cohesion, task cohesion, performance, Tunisian professional football

\section{INTRODUCTION}

Cohesion is a concept that has been the subject of a great deal of research. Certainly, The operation of sports teams is a complex phenomenon. In victory as in defeat many elements are to be taken into account. The obligation of the results inherent in modern football, the pressures of time, the conflicting relations, the pressures of the match, the questioning of the physical integrity and the fear of failure, are all factors that are affected by the cohesion. of the team. Moreover, in the past, studies examining the relationship between team cohesion and sports performance reveal inconsistent conclusions. To clarify the nature of this relationship, Albert Carron and his colleagues conducted a meta-analysis on the relationship between cohesion and athletic performance.

This meta-analysis included a total of 46 studies, 9,988 athletes, and 1,044 Canadian teams. The results showed a moderate to high positive relationship between social and operational cohesion on the one hand and performance in sport on the other. Albert Carron, AV, Colman, MM, Wheeler, J., \& Stevens, D. (2002) (4) Moreover, in analyzing the type of cohesion, Carron and his colleagues reported that social cohesion and cohesion at the task (operative) were related to performance. This means that both dimensions of cohesion are important for performance. On the other hand, there is other research that opposes Carron's notion of meta-analysis, most of which suggests a positive relationship between operational dimension and performance (Bergeles and Hatziharistos, 2003 (5) Mullen and Copper, 1994 (6)) and neglecting the social dimension. For Mullen and Copper The operational dimension remains the most relevant for translating the relationship between cohesion and performance. Through these different conceptual contradictions, we will in this article highlight the dimension (s) that could contribute to developing sports performance in a high-level sports context. To do so, we ask ourselves the following questions and questions : (i) What is the dimension of cohesion (operative, social or general) most relevant for a better performance ? (ii) What are the determining factors for cohesion, operation and social ? 
In the late 1920s, research on teamwork yielded astonishing conclusions that performance is not related to changing objective productivity factors (duration or frequency of breaks), but rather to the emergence a "sense of belonging to the group" and the adherence of all workers to productivity goals (Buton, Fontayne, and Heuzé, 2006 (7)). This early work, which focused on the importance of human relations in the work teams, guided subsequent studies. Cohesion refers to a theoretical construct that accounts for the "coherence of a group" (Carron et al, 2005 (8)), the quality and the intensity of the relationships that unite its members. Its Latin etymology (cohaesum, cohaerere) refers to being tied together, to a force by which two things adhere to each other. Applied to the group, cohesion expresses a strong, almost indestructible link that unites the members of a group. Albert Carron, an eminent specialist in the social psychology of sport, has worked extensively on the concept of cohesion. It defines cohesion as "a dynamic process reflected in the group's tendency to remain bound and remain united in the pursuit of its instrumental goals and / or the satisfaction of the affective needs of members" (Carron, Brawley and Widmeyer, 1998, (9)). This definition highlights four major characteristics of cohesion: its multidimensional, dynamic, instrumental and affective nature.

Carron and his colleagues (Carron, Brawley, Widmeyer, 1985 (10)) proposed a theoretical framework that captures the multidimensional, dynamic, instrumental and affective nature of cohesion. The latter distinguish two dimensions in cohesion. The first term integration of the group "Integration Group": GI) is defined as "the individual perception of the proximity, the similarity of the links within a group and the perception of the degree of unity of the field action of the group ".

The second dimension, called Individual Attraction to the Group (ATG), is defined as "the totality of the individual feelings of subjects towards the group, the desire to be accepted and the feelings of the group. other members of the group ". So it's both the individual motivations to stay in the group and the personal feelings about the group. Each of these dimensions can be expressed according to two orientations : social and operative.

We must therefore distinguish four factors of cohesion:

- The individual task Group (AIO) reflect the individual feelings of the athletes for group activity, team goals, group play level ...

- The individual social attractions for the group (AIS) reflects the attraction for friendships in the group.

- The task integration of the group (IOG) refers to the individual perceptions of athletes about the unity of their team in relation to their tasks and objectives, integration into a group that works well (or not).

- The social integration of the group (ISG) refers to the individual perceptions of the members on the social unit of the group, a related group, a group of friends ...

Nevertheless, a consensus about the dimensions of the model of Carron et al (1985) (10) seems to emerge in the sports field. The majority of the work adopts this conceptualization to study the cohesion of sports groups. They consider that a fairly large proportion of the variability in the cohesion of the sports teams is associated with the four factors of their model, but do not rule out the possibility that other dimensions may also be relevant for reporting cohesion in the field. athletic. In addition, Carron and colleagues point out that cohesion is a multidimensional dynamic construct valued from the feelings of team members and whose influence on behavior seems essential for the group and the individual. This multidimensional design makes it possible to consider the combined and simultaneous effects of the attraction / integration and social / operational dimensions, and thus to overcome some contradictory results pointed out in meta-analyzes dealing with the cohesionperformance relationship.Finally, this multidimensional conception also implies that several dimensions can be responsible for the fact that the members of the group remain united in the pursuit of their objectives and that the importance of each dimension can change according to the nature or the moment of life. of the group. In fact, several researchers have adopted the Carron model for their analyzes; Even the most recent, as well as, the works of A.J Benson et al (2016) on the relationship between cohesion and performance through the comparison between the Czech and Slovak athletes who belong to the 22 handball teams. Also the work of Léo Gonzales-ponce et al (2015) on the "collective efficiency" of a team in the period of competition. Other work on motivation created by 
the coach and its positive impact on the cohesion of a team while keeping the spirit of work in staff (Gracìa-calvo 2014). All this work and others we deployed the multidimensional model of Carron.

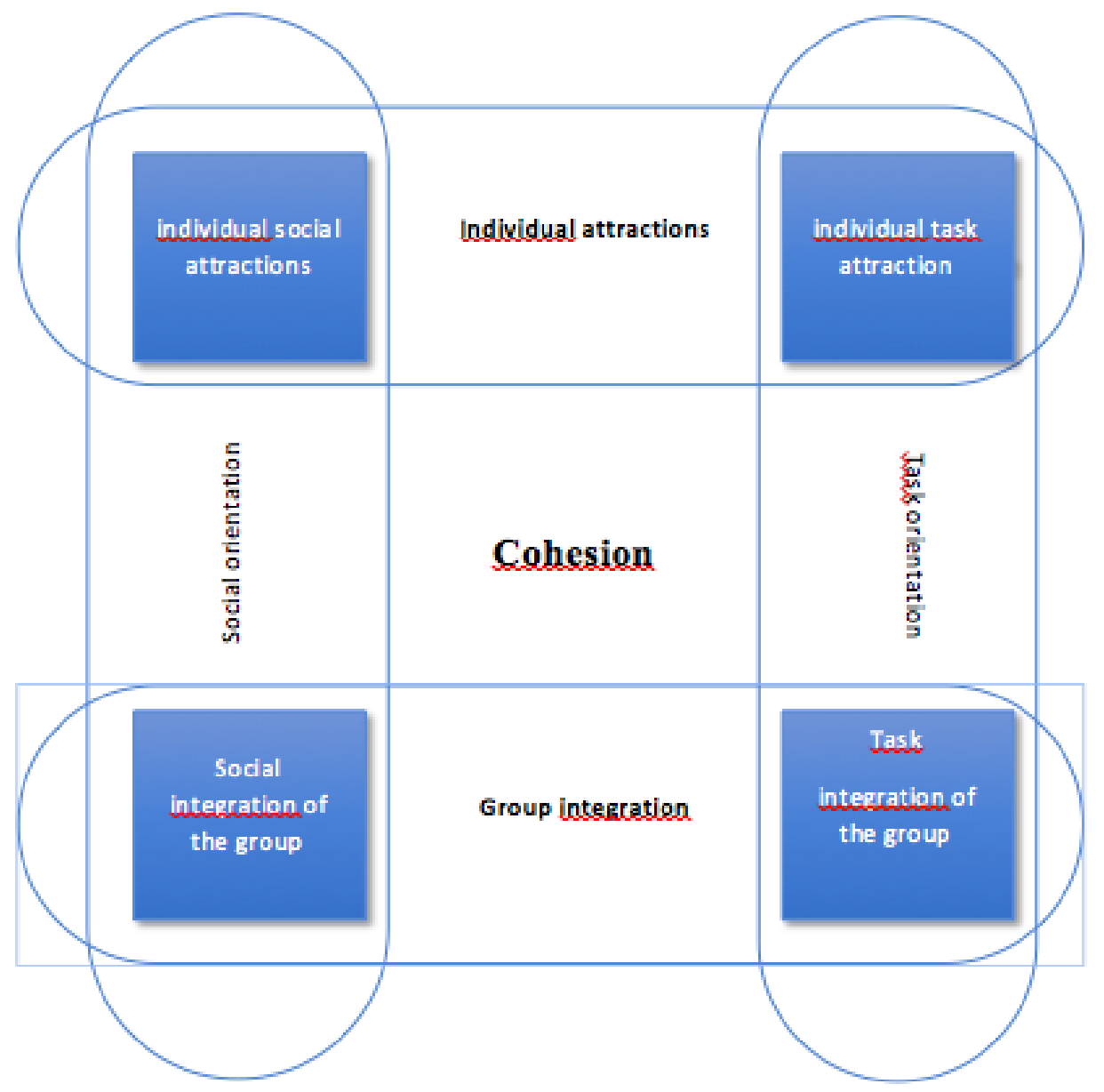

Figure1: Conceptual model of cohesion in sport (Carron, Widmeyer and Bradley, 1985 (10))

The main objective of our study is to explain the relationship between cohesion and performance ; that is to say, to identify the degree of influence of the social cohesion as well as the operative one in the bodily sports practices. We propose to carry out an exploratory study through a questionnaire in order to better understand the relationship between cohesion and performance. In addition, this exploratory study makes it possible to explore the fundamental question in a specific context (Tunisian context). More specifically, the purpose of this first phase is to explore and identify intragroup relationships and their influences on performance. We propose as hypotheses either; H1: The most cohesive teams on the operative plan are the most efficient. Either, H2: The most socially cohesive teams are the most successful. Let $\mathrm{H} 3$ be: The best performing teams are socially and operationally cohesive. For the first hypothesis, we are inspired by the work of (Bergeles and Hatziharistos, 2003) or we consider that the operating dimension is the most influential dimension to the success of a team. So, the social dimension is neglected in the context of professionalism. Moreover, our second hypothesis, considers that the secret of success of the sports team is bound imperatively by the degree of social cohesion. As long as the team is socially cohesive, it will overcome all the operating obstacles proposed throughout the competition. Finally, a third hypothesis highlights the two dimensions, social and operational, for the team to be balanced and efficient (Carron et al 2002).

\section{METHODS}

\subsection{Population}

Our study population includes a total of 150 footballers belonging to six clubs of the Tunisian championship, playing in the first division. For information, 15 of the 150 players refused to participate in the experience. For this study, 135 players really participated in our experience. (M age 
$=25.20, \mathrm{SD}=3.903)$ the first team $(\mathrm{E} 1)(\mathrm{M}$ age $=23.92, \mathrm{SD}=4.491)$ the second team $(\mathrm{E} 2)(\mathrm{M}$ age $=$ $27.21, \mathrm{SD}=2.974)$ the third team $(\mathrm{E} 3)(\mathrm{M}$ age $=25.04, \mathrm{SD}=3.895)$ the fourth team $(\mathrm{E} 4)(\mathrm{M}$ age $=$ $25.43 \mathrm{SD}=4.460)$ fifth team $(\mathrm{E} 5)(\mathrm{M}$ age $=24.39 \mathrm{SD}=3.388)$ and the sixth team $(\mathrm{E} 6)(\mathrm{M}$ age $=$ 25.41 SD $=3.422$ ).

\subsection{Investigative Tools}

The measurement of cohesion: Heuzé and Fontayne (2002) proposed a translated version of the original English version of the Carron et al. (GEQ) (Environmental Questionnaire Group), which is the questionnaire on the environment. of the group (QAG). They made it possible to demonstrate the validity, the construct fidelity and the predictive validity of a Francophone measure of cohesion. A new transcultural validation translated into Arabic by Boughattas and Kridiss (2016). The GAQ has 18 items and measures four factors of cohesion:

- Individual operating attractions for the group (AOG, four items: 2, 4, 6, 8),

- Individual social attractions for the group (ASG, five items: 1, 3, 5, 7, 9),

- Operative integration of the group (IOG, five items: $10,12,14,16,18$ ),

- Social integration of the group (ISG, four items: $11,13,15,17$ ).

Responses are reported on 9-point Likert scales ranging from (1) "strongly disagree" to (9) "strongly agree". The scores on items 1, 2, 3, 4, 6, 7, 8, 11, 13, 17 and 18 are reversed so that high scores reflect high perceptions of cohesion. The score of each of the four factors corresponds to the average of the athlete's scores on the items constituting the scale; high scores reflect high perceptions of cohesion.

The AOG and IOG factors define the operational cohesion, ASG and ISG define social cohesion.

\subsection{Procedures}

For our population, we contacted the clubs, coaches and even players of each team directly after the end of the first phase of the season 2017/2018 phase of the winter break. Once the coaches' agreement was obtained, we went to the training area of each team. The measurements were made during the week, before a training session and not during the match days. We thought that the result of the match could have a strong influence on players' responses to emotional instability following a victory or defeat on match day. The players usually completed the questionnaires either in small groups of 4-5 or with all the team members at the same time, with our presence for the explanation of the items to the players in order to eliminate any confusion and misunderstanding during the reply. Leaders, coaches and others do not participate in the running of the experience as we also believe that it may affect players' responses.

\subsection{Performance Measurement}

The success of the team was defined as the percentage of wins for all matches played in the first phase of the championship for each team. The percentage of success was calculated by dividing the number of points obtained according to the outcome of the match ( 3 points for a victory, 1 point for a draw, 0 points for a defeat) by the maximum number of points that can be scored. awarded in case of victory (Van-Yperen and Duda, 1999).

Table1: Ranking and performance of the teams participating in the experiment

\begin{tabular}{|l|l|l|l|l|l|l|}
\hline \multicolumn{1}{|c|}{ Ranking } & Code & Points & Play & Win & Draw & lost \\
\hline 1 & E1 & 30 & 14 & 9 & 3 & 2 \\
\hline 3 & E2 & 24 & 14 & 6 & 6 & 2 \\
\hline 4 & E3 & 22 & 14 & 6 & 4 & 4 \\
\hline 5 & E4 & 15 & 14 & 3 & 6 & 5 \\
\hline 6 & E5 & 12 & 14 & 2 & 6 & 6 \\
\hline 7 & E6 & 12 & 14 & 3 & 3 & 8 \\
\hline
\end{tabular}

\section{RESULTS}

\subsection{Statistical Analysis of the Model and Variables}

First, we need to present the whole of our construct in a general way and check the reliability statistics as well as the scale and item. The Cronbach coefficients of cohesion in general are 0.619. Some 
authors put 0.75 or 0.80 as the minimum threshold of acceptability, while others are only 0.60 . Knowing that when the alpha value is 0.70 , the standard error of measurement is equal to or more than half $(0.55)$ of the standard deviation of the total score distribution. For scale statistics across our questionnaire, we find that the means $=(22.39)$ the variance $=(23.76)$ the standard deviation $=(4.87)$ and the number of summer elements (4). We can thus affirm that our scale allowing to evaluate the dimension "Cohesion" and its components :Individual operating attractions ; Individual social attractions ; Operative integration of the group ; Social integration of the group.

- Operative individual attraction and operative integration of the group presents the operational cohesion.

- The individual social attraction and social integration of the group presents social cohesion.

These different components are measured on a nine point Likert scale ranging from "strongly disagree (1)" to "strongly agree (9)". The minimum value for this scale is 4 and the maximum value is 36 . Currently, participants are getting an average of 22.39 (ie 4.8). So we can say that the construct is valid.

Table2: Item Statistics

\begin{tabular}{|l|l|l|l|}
\hline & Mean & SD & N \\
\hline AIS & 5,7822 & 1,55946 & 135 \\
\hline AIO & 6,4815 & 1,85295 & 135 \\
\hline IOG & 4,7704 & 2,09698 & 135 \\
\hline ISG & 5,3630 & 1,57070 & 135 \\
\hline
\end{tabular}

Abbreviation: SIA = Social Individual Attraction / OIA = Operative Individual Attraction

$\mathrm{OIG}=$ Operative integration with the group $/ \mathrm{SIG}=$ Social integration in the group

Table.3, shows all the elements measured on a nine-point scale. The average is 4.5 . This means that the 135 participants agree on average with the statements about SIA, OIA, OIG, SIG.

Table3: The correlation between social cohesion and operational cohesion with performance

\begin{tabular}{|l|l|l|l|l|}
\hline & Corrélations & S.C & O.C \\
\hline & Mean $($ S.D $)$ & PERFORMANCE & & \\
\hline PERFORMANCE & $19,20(6,763)$ & 1 & & \\
\hline S.C & $5,57(1.22)$ &, $515^{* *}$ & 1 & 1 \\
\hline O.C & $5,62(1.57)$ &, $724^{* *}$ & - & \\
\hline & $* *$ The correlation is significant at the 0.01 level (bilateral). & \\
\hline
\end{tabular}

Abbreviation: $\mathrm{SC}=$ social cohesion / $\mathrm{OC}=$ operative cohesion

The correlation table comparing social and operative variables with performance shows positively significant relations between social cohesion and performance $\left(\mathrm{r}=, 515^{* *}\right)$ and also a greater significance between operational cohesion and performance $(\mathrm{r}=, 724 * *)$.

\subsection{Descriptive Analysis of the Relationship between Social, Operational and Performance Cohesion}

Then, in this section we will reveal the correlations between the dependent variables and the independent variables. As well as, the comparison between the different factors of cohesion in order to explain the effect of the relational dynamics between the factors mentioned below on the variation of the performanc.

This third figure presents the averages of the social and operational cohesion of the teams according to their performances (let's start with the team (1) the most efficient until the team (6) the worst performer). Where, we note a significant relationship between the two dimensions of cohesion with performance. In addition, all teams with averages above $4.5(\mathrm{~m}=4.5)$. By comparing the social and operational dimensions, we can see that the operation is more important than the social one in high performing teams (eg team 1). On the other hand the social and more important than the operative one within the less performing teams (ex: team 6). 


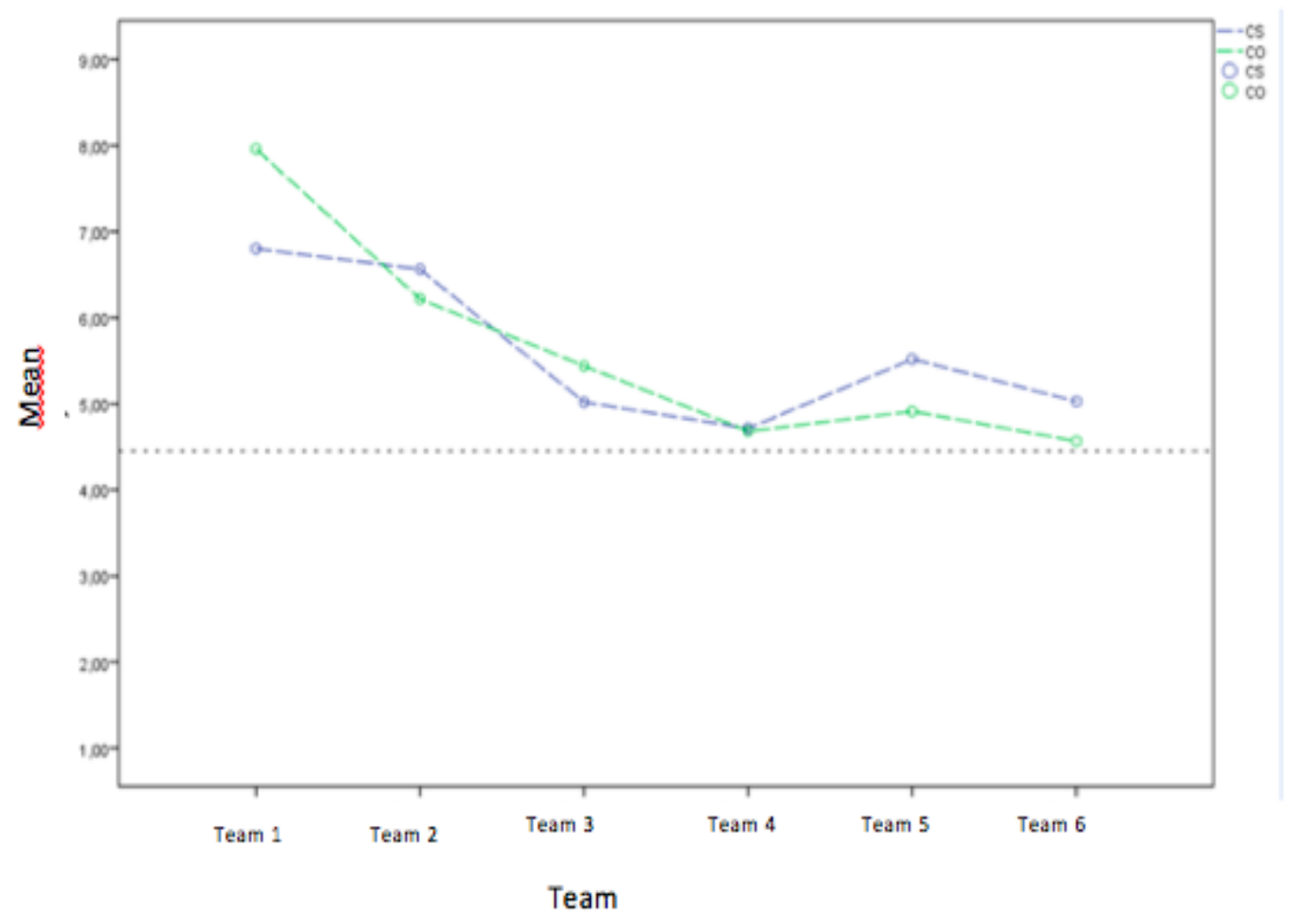

Figure2: The relationship between team performance and social and Task cohesion

Abbreviation: $\mathrm{SC}=$ social cohesion $/ \mathrm{OC}=$ operative cohesion

Table4: Average Social and Operational Cohesion by Team

\begin{tabular}{|c|c|c|c|}
\hline \multicolumn{2}{|r|}{ Team } & CS & $\mathrm{CO}$ \\
\hline \multirow[t]{3}{*}{1} & Mean & 6,8042 & 7,9625 \\
\hline & $\mathrm{N}$ & 24 & 24 \\
\hline & $S . D$ & ,67117 &, 58356 \\
\hline \multirow[t]{3}{*}{2} & Mean & 6,5658 & 6,2211 \\
\hline & $\mathrm{N}$ & 19 & 19 \\
\hline & $S . D$ & 1,14989 & 1,19699 \\
\hline \multirow[t]{3}{*}{3} & Mean & 5,0219 & 5,4427 \\
\hline & $\mathrm{N}$ & 24 & 24 \\
\hline & $S . D$ & ,90366 & ,95589 \\
\hline \multirow[t]{3}{*}{4} & Mean & 4,7174 & 4,6837 \\
\hline & $\mathrm{N}$ & 23 & 23 \\
\hline & $S . D$ & 1,00647 & 1,06937 \\
\hline \multirow[t]{3}{*}{5} & Mean & 5,5222 & 4,9153 \\
\hline & $\mathrm{N}$ & 18 & 18 \\
\hline & S.D & ,58998 & 1,18735 \\
\hline \multirow[t]{3}{*}{6} & Mean & 5,0306 & 4,5694 \\
\hline & $\mathrm{N}$ & 27 & 27 \\
\hline & $S . D$ & 1,06668 & 1,07496 \\
\hline \multirow[t]{3}{*}{ Total } & Mean & 5,5726 & 5,6259 \\
\hline & $\mathrm{N}$ & 135 & 135 \\
\hline & $S . D$ & 1,21542 & 1,57409 \\
\hline
\end{tabular}

Abbreviation: $\mathrm{SC}=$ social cohesion $/ \mathrm{OC}=$ operational cohesion $/ \mathrm{N}=$ number

The table above shows the exact averages of each team in terms of social and operational cohesion. In addition, he proposes the standard deviation and the number of participants. It can be noted that, not only the averages of the (CS) and (CO) are higher in the high-performance teams (1 and 2) compared to the lower-performing teams (5 and 6), but also the standard deviation is also> 1.0 for the high- 
performance teams (team1 - e- $\mathrm{t}=((\mathrm{CO}=, 583)(\mathrm{CS}=, 671))$. Then it is $<1.0$ for the lower performing teams (team 6 - e-t $=((\mathrm{CO}=1.574)(\mathrm{CS}=1.215))$ However, these averages remain general with respect to the different cohesion factors that we will count as presented in the following figure.

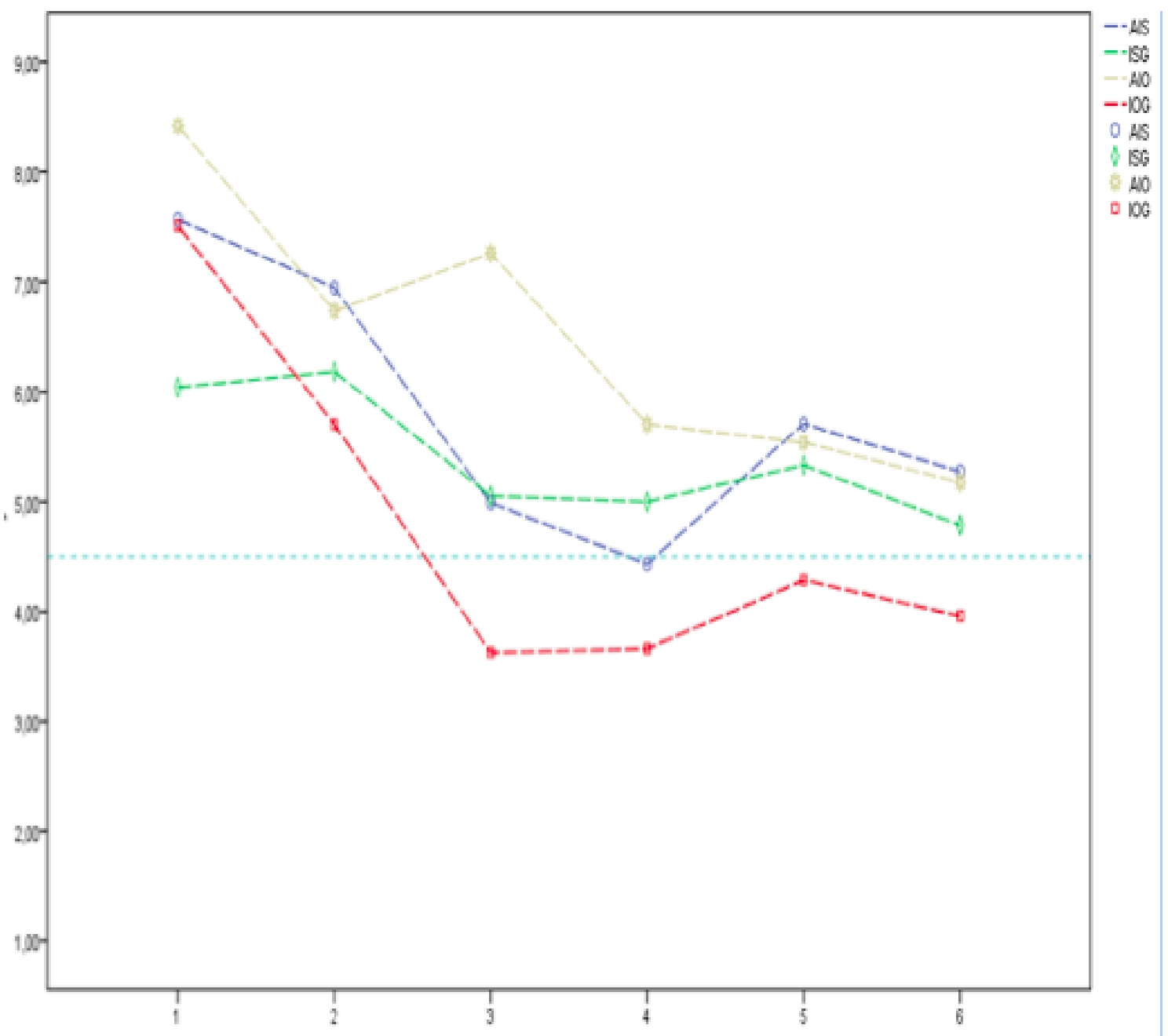

Figure3: The relationship between team performance and the four factors of cohesion

This figure presents in detail; individual social attraction (AIS), individual operative attraction (AIO), group social integration (ISG) and team operational integration (IOS). Let's start with the top performing team (1) to the worst performing team (6). We notice that the averages fall in most of the time as soon as the performance decreases.

The most interesting result is the operational integration to the group (I.O.G), ie, what the player thinks of his teammates on the operative plane. It is found that Teams 1 and 2 (performers) are above average ( $M=4.5)$.

Table5: Averages of the four factors of team cohesion

\begin{tabular}{|c|c|c|c|c|c|}
\hline \multicolumn{2}{|r|}{ ÉQUIPE } & AIS & ISG & AIO & IOG \\
\hline \multirow[t]{3}{*}{1} & Mean & 7,5667 & 6,0417 & 8,4167 & 7,5083 \\
\hline & $\mathrm{N}$ & 24 & 24 & 24 & 24 \\
\hline & $S . D$ & ,69449 & 1,02328 & ,41485 & ,90020 \\
\hline \multirow[t]{3}{*}{2} & Mean & 6,9474 & 6,1842 & 6,7368 & 5,7053 \\
\hline & $\mathrm{N}$ & 19 & 19 & 19 & 19 \\
\hline & $S . D$ & 1,17916 & 1,60909 & 1,42516 & 1,45200 \\
\hline \multirow[t]{3}{*}{3} & Mean & 4,9917 & 5,0521 & 7,2604 & 3,6250 \\
\hline & $\mathrm{N}$ & 24 & 24 & 24 & 24 \\
\hline & $S . D$ & 1,07052 & 1,63185 & 1,50087 & 1,67157 \\
\hline \multirow[t]{2}{*}{4} & Mean & 4,4348 & 5,0000 & 5,7065 & 3,6609 \\
\hline & $\mathrm{N}$ & 23 & 23 & 23 & 23 \\
\hline
\end{tabular}


Comparative Analysis of Social Cohesion and Task Cohesion in the Context of Tunisian Professional Football

\begin{tabular}{|l|l|l|l|l|l|}
\hline & $S . D$ & 1,34658 & 1,64800 & 1,28729 & 1,69966 \\
\hline \multirow{5}{*}{5} & Mean & 5,7111 & 5,3333 & 5,5417 & 4,2889 \\
\cline { 2 - 6 } & $\mathrm{N}$ & 18 & 18 & 18 & 18 \\
\cline { 2 - 6 } & S.D &, 97552 & 1,49755 & 1,83562 & 1,82817 \\
\hline \multirow{3}{*}{6} & Mean & 5,2741 & 4,7870 & 5,1759 & 3,9630 \\
\cline { 2 - 6 } & $\mathrm{N}$ & 27 & 27 & 27 & 27 \\
\cline { 2 - 6 } & S.D & 1,26022 & 1,55152 & 1,88722 & 1,63992 \\
\hline \multirow{3}{*}{ Total } & Mean & 5,7822 & 5,3630 & 6,4815 & 4,7704 \\
\cline { 2 - 6 } & $\mathrm{N}$ & 135 & 135 & 135 & 135 \\
\cline { 2 - 6 } & S.D & 1,55946 & 1,57070 & 1,85295 & 2,09698 \\
\hline
\end{tabular}

The fifth table presents the exact averages of the different factors (AIS, ISG, AIO, IOG) and the standard deviations for each team. We notice that the standard deviations become more and more important for all the factors of cohesion going from the most powerful until the successful months. This means that the best performing teams are more consistent in their responses (let's have the same vision) than the less successful ones.

\section{DISCUSSION}

The functioning of sports teams is a complex phenomenon that we have sought to decipher. It seemed important to us to study two essential notions of this functioning: cohesion and performance. The main objective of this research is to evaluate the relationship between the cohesion and sports performance of Tunisian footballers (high level teams in Tunisia). We consider that our sampling is representative because it presents more than $30 \%$ of the exhaustive population of high level players (ie (6) teams out of 16). According to the analysis of the reliability of the questionnaire on the group's atmosphere of our study population, we noticed that the internal consistency of the scales appeared rather weak.

Similarly, the factors of social and operative cohesion did not appear correlated with each other. Indeed, Estabrooks and Carron (2000) point out that the use of the questionnaire (GEQ) and its translations, with a senior public practicing regular physical activities, poses problems of internal consistency of the scales. According to J. Barnette (2000), these difficulties would be one of the major factors in reducing the reliability and validity of scales using affirmative and negative items. This question was raised by Eys, Carron et al. (2007) for the Anglophone Measure of Cohesion (GEQ).

Compared to other works on the relationship between cohesion and performance (AJ Benson et al., 2016) by the comparison between young Czech and Slovak sportsmen in the evolution process during the championship and the adaptation of the Carron questionnaire et al. 2009). Our results, confirms the hypothesis that social and operative cohesion, are two important elements for the success of the team (Carron, A.V., Colman, M.M., Wheeler, J., \& Stevens, D. 2002). Performance positively influences both dimensions of cohesion. But according to the averages presented (Table 3 ) of the correlation between the two dimensions and the performance. It can be seen that the operational cohesion is strongly correlated with the performance in relation to the correlation of social cohesion.

In particular, the averages of the operational cohesion are more important for the high-performance teams. But social cohesion is more important than the operative when it is about a less performing team (example, team 5 and 6).

Other research concludes that there is a combined effect of social and operational cohesion that should both be elevated to positively influence performance (Zaccaro and McCoy 1988, Carron and Colman et al. Martens and Peterson (1971 : 58), cited in Turman (2003), suggest the existence of "a circular relationship between satisfaction, cohesion and success. The most cohesive teams being the most successful teams and the most successful teams having greater satisfaction with their participation than the less successful teams. In this quote appears another concern still hanging today: is cohesion a determinant or a consequence of performance? Many studies deal with this question (Carron, Colman, et al., 2002, Chang and Bordia, 2001, Davids and Nutter, 1988, Grieve, Whelan, and Meyers, 2000, Mullen and Copper, 1994, Turner, 1981, Benson and 2016). For Chang and Bordia, (2001), the most important effect is that of performance on cohesion. Their results suggest that the cohesion changes engendered by the performance are stronger than the performance changes generated by the cohesion. Researches examining the meaning of the cohesion-performance relationship then refined the analysis 
by observing the role of the different dimensions present in the multidimensional approach of cohesion proposed by Caron et al. (1985).

This theoretical perspective can open avenues for longitudinal research to understand this triangular relationship between operational, social and performance cohesion. To conclude, this work allowed us to highlight the relationship between cohesion and performance in a football environment in top teams, as well as to assess the impact of cohesion on performance in a context and a Tunisian culture different from those previously analyzed. Really it was difficult to address this world of professionalism in football that we feel is delicate. However, in reviewing, all analyzes conducted in this study, prove a number of conclusions similar and contradictory to previous studies. Mainly, we can say that cohesion is a determining factor in the performance of the teams, whose most cohesive teams are the best performing teams. The results obtained also showed that in collective sports like football, the success of a team is strongly linked to the social and operative cohesion of its members but it favors one dimension on the other according to the performance. Undoubtedly, these results invite coaches and researchers not to neglect the development of social and operational cohesion within the team because these two variables can have a significant effect on the success of the team.

\section{CONCLUSION}

In this study we focused our research on exploring the dynamics of cohesion in professional football teams. In the literature, there is an important contradiction that puts in question the (social and operative) demotions and the factors (integration and attraction, social and operative) are it determining? And what are among these is the most determining for the success of a team? In our research it has been shown that both dimensions are important for the performance of a professional football team. The originality of this study is to focus on the most decisive factor and the most neglected by the professional teams that of the operational integration to the group which designates the individual perceptions of footballers on the unity of their team compared its tasks and objectives. This unity of perceptions is the key to the success of the top football team.

\section{REFERENCES}

[1] Arrow, H., Poole, M. S., Henry, K. B., Wheelan, S., \& Moreland, R. (2004). Time, change, and development: The temporal perspective on groups. Small Group Research, 35, 73-105.

[2] Alex J. Benson Pavol Siska, Mark Eys , Silvia Priklerova_, Pavel Slepicka (2016) A prospective multilevel examination of the relationship between cohesion and team performance in elite youth sport / Psychology of Sport and Exercise 27 (2016) 39-46

[3] Arrow, H., McGrath, J. E., \& Berdahl, J. L. (2000). Small groups as complex systems: Formation, coordination, development, and adaptation. Thousand Oaks, CA: Sage. isEp?

[4] Barnette, J. J. (2000). Effects of stem and Likert response option reversals on survey internal consistency: If you feel the need, there is a better alternative to using those negatively worded stems. Educational and Psychological Measurement, 60 , 361-370.

[5] Bergeles, N., \& Hatziharistos, D. (2003). Interpersonal attraction as a measure of estimation of

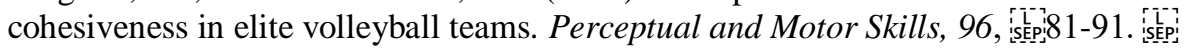

[6] Brawley, L. R. (1998). Foreword. In A. V. Carron \& H. A. Hausenblas (Eds.), Group iscepidynamics in sport (2nd ed.). Morgantown, WV: Fitness Information Technology. SsEp?

[7] Brawley, L. R., Carron, A. V., \& Widmeyer, W. N. (1988). Exploring the relationship between cohe- sion and group resistance to disruption. Journal of Sport \& Exercise Psychology, 10, 199-213. is

[8] Buton, F., Fontayne, P., \& Heuzé, J. P. (2006). La cohésion des groupes sportifs : évolutions conceptuelles, mesures et relations avec la performance. Science \& Motricité, 59, 9-45. iscep?

[9] Carron, A.V. (1980). Social psychology of sport. Ithaca, NY: Mouvement.s[s:

[10] Carron, A. V., \& Hausenblas, H. A. (1998). Group dynamics in sport (2nd ed.). isepes Morgantown, WV: Fitness Information Technology. SLEP:

[11] Carron, A. V., Widmeyer, W.N., \& Brawley, L.R. (1985). The development of an isepinstrument to assess cohesion in sport teams: The Group Environment Questionnaire. [SEp: Journal of Sport Psychology, 7, 244266. is:

[12] Carron, A.V., \& Brawley, L.R. (2000). Cohesion: Conceptual and measurement issues. isẹpiSmall Group Research, 31, 89-106. ișpi?

[13] Carron, A. V., Colman, M. M., Wheeler, J., \& Stevens, D. (2002). Cohesion and iseiperformance in sport: 


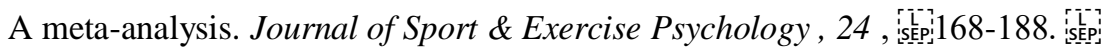

[14] Carron, A. V., \& Garvie, G. T. (1978). Compatibility and successful performance. isteperiperceptual and

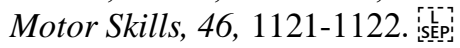

[15] Carron, A. V., Hausenblas, H. A., \& Eys, M. A. (2005). Group dynamics in sport (3rd ise-ed.). Morgantown, WV: Fitness Information Technology. in'pipi

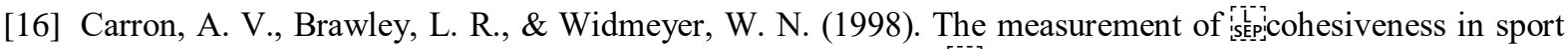

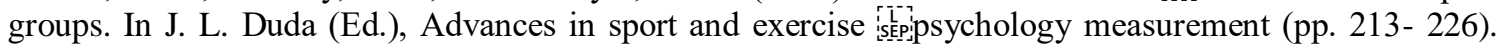
Morgantown, WV: Fitness Information Technology.

[17] Cota, A.A., Evans, C.R., Dion, R.S., Kilik, L., \& Longaman, R.S. (1995). The structure of group cohesion.

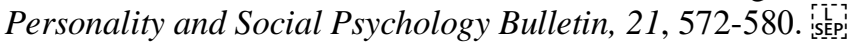

[18] Davids, K., \& Nutter, A. (1988). The cohesion-performance relationship of English National League

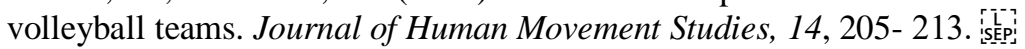

[19] De Visscher, P. (2001). La dynamique des groupes d'hier à aujourd'hui. Paris: Presses Universitaires de France. istipi:

[20] Donnelly, P., Carron, A. V., Chelladurai, P., \& Canadian Association for Health, Physical Education and Recreation. (1978). Group cohesion and sport. Calgary, Alta.: University of Calgary. șêp.

[21] Dion, K. L. (2000). Group cohesion : From «Field of Forces » to multidimensional construct. Group Dynamics : Theory, Research and Practice, 4, 7-26.

[22] Estabrooks, P. A., \& Carron, A. V. (2000). The Physical Activity Group Environment Questionnaire : An instrument for the assessment of cohesion in exercise classes. Group Dynamics: Theory, Research, and Practice, 4, 230-243.

[23] Eisler, L. Spink, K.S. (1998) Effects of scoring configuration and task cohesion on the perception of psychological momentum. The Journal of Sport \& Exercise Psychology .20: 311-320. is.pín

[24] Eys, M. A., Carron, A. V., Bray, S. R., \& Brawley, L. R. (2007). Improving the psychometric properties of a measure of group cohesion: The Group Environment Questionnaire. Journal of Sport \& Exercise

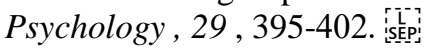

[25] Festinger, L., Schachter, S., \& Back, K. (1950). Social pressure in informal groups. New-York : Harper and Brothers. "is

[26] Fisher, G. (1990). Les domaines de la psychologie sociale : Le champ du social, Paris, Dunod. íșep:

[27] Fisher, G. (1991). Les domaines de la psychologie sociale, 2 : processus du social, Paris,

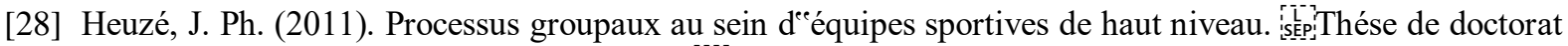
inédite. Université joseph fourier Gronoble.

[29] Heuzé, JP., Fontayne, P. (2002). Questionnaire sur leeambiance du groupe : A French șEẹpLanguage Instrument for Measuring Group Cohesion. Journal of Sport \& Exercise

[30] Lewin, K. (1959). Psychologie dynamique. Les relations humaines, Paris : Presses iṣ̌p:Universitaires de

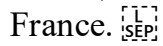

[31] Martens, R. \& Peterson, J.A. (1971). Group cohesiveness as a determinant of success and member satisfaction in team performance. International Review of Sport Sociology, 6, $49-61$.

[32] McDougall, W. 1920-1921. Four Cases of „Regression“e in Soldiers. Journal of Abnormal Psychology 15: 136-156

[33] Mento A. J., Steel, R. P., \& Karren, R. J. (1987). A meta-analytic study of the effects of goal setting on

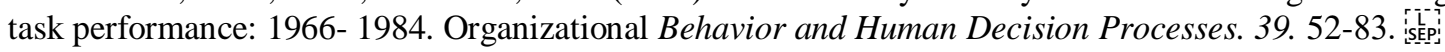

[34] Michinov, E. (2001). L"eattraction interpersonnelle : un concept en évolution. Les Cahiers Internationaux de Psychologie Sociale, 50, 11-26. [í⿴囗十

[35] Mullen, B., \& Copper, C. (1994). The relation between group cohesiveness and performance: An integration. Psychological Bulletin, 115, 210-227. [is

[36] Moreno, J. L. (1934). Who Shall Survive? Washington, DC: Nervous and Mental Disease Publishing Company. ichepin

[37] Randsley de Moura, G., Leader, T., Pelletier, J., \& Abrams, D. (2008). Prospects for group processes and intergroup relations research: A review of 70 years ${ }^{e e}$ progress. Group Processes \& Intergroup Relations, $11,575-596$.

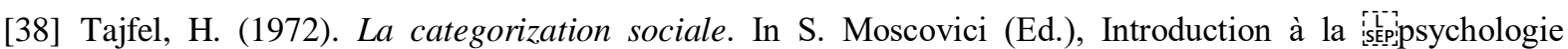

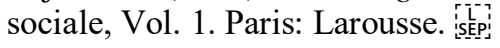

[39] Spink K. S., Carron A. V. (1992). Group cohesion and adherence in exercise classes. Journal of Sport and Exercise Psychology, 14, 78-86. 
[40] Tajfel, H., \& Turner, J. C. (1979). An integrative theory of intergroup conflict. In W. G. Austin \& S. Worchel (Eds.), The social psychology of intergroup relations. Monterey, CA: Brooks/Cole.

[41] Tajfel, H. (1982). Social identity and intergroup relations. Cambridge University Press.

[42] Widmeyer, W., Brawley, L., \& Carron, A. (1990). Group size in sport. Journal of Sport \& Exercise Psychology, 12, 177-190. iscepin

[43] W. Boughattas, N. Kridis (2016 / Pratiques psychologiques 22 301-315

[44] Van-Yperen, N.W., \& Duda, J.L. (1999). Goal orientations, beliefs about success, and performance improvement among young elite Dutch soccer players. Scandinavian journal of medicine \& science in sports, 9, 358-364.

Citation: Ali ELLOUMI, et.al. " Comparative Analysis of Social Cohesion and Task Cohesion in the Context of Tunisian Professional Football" International Journal of Sports and Physical Education (IJSPE), vol 5, no. 4, 2019, pp. 28-38. doi: http://dx. doi.org/10.20431/2454-6380.0504005.

Copyright: (C) 2019 Authors. This is an open-access article distributed under the terms of the Creative Commons Attribution License, which permits unrestricted use, distribution, and reproduction in any medium, provided the original author and source are credited. 